\title{
NILAI-NILAI KARAKTER RITUAL KING HO PING SEBAGAI SUMBER BELAJAR IPS
}

\author{
Eko Prasetyo Utomo.
}

\author{
SMP Negeri Model Terpadu Bojonegoro
}

\section{Info Artikel}

\section{Sejarah Artikel:}

Disubmit Juni

Direvisi Juni

Diterima Juni

\section{Keywords:}

Character, King Ho

Ping, Learning

Resources, Social Studies

\begin{abstract}
Abstrak
Tujuan dalam penelitian ini yaitu untuk mengetahui prosesi ritual King Ho Ping dan nilai-nilai karakter dalam ritual King Ho Ping sebagai sumber belajar IPS. Penelitian ini menggunakan pendekatan kualitatif dengan desain penelitian fenomenologi. Penelitian ini berlokasi di kelenteng Hok Swie Bio Kabupaten Bojonegoro. Hasil penelitian menunjukkan bahwa ritual King Ho Ping dimulai dengan acara pergelaran wayang kulit dilanjutkan dengan karawitan dan atraksi Liong serta Barongsai. Puncak ritual dilakukan sembahyang sebanyak tiga kali putaran dan diakhir bunyi gendering sebagai tanda prosesi rebutan gunungan dimulai. Sub nilai-nilai karakter yang muncul yaitu 1) menghargai perbedaan agama dan kepercayaan; 2) teguh pendirian; 3) kerja sama antar pemeluk agama; 4) apresiasi budaya bangsa sendiri 5) menjaga kekayaan budaya bangsa; 5) menghormati keragaman, suku, agama dan budaya; 6) tolong menolong; 7) anti diskriminasi; 8) pembejaran sepanjang hayat; dan 9) tanggung jawab. Nilai-nilai karketer dalam ritual King Ho Ping dapat diintegrasikan dalam materi pembelajaran IPS dalam desain pembelajaran IPS terpadu tematik berdasarkan topik yaitu integrasi kehidupan sosial dengan keterpaduan geografi, sejarah, sosiologi, dan ekonomi.
\end{abstract}

\section{Abstract}

The purpose of this research is to find out the King Ho Ping ritual procession and character values in the King Ho Ping ritual as a source of social studies learning. This research uses a qualitative approach with a phenomenological research design. This research is located in the Hok Swie Bio temple in Bojonegoro Regency. The results showed that the King Ho Ping ritual began with a shadow puppet show continued with musical performances and Liong and Barongsai attractions. The climax of the ritual is to pray three times and the end of the ringing signal as a sign of the procession of the gunungan battle begins. Sub character values that arise are 1) respecting differences in religion and belief; 2) firm stand; 3) cooperation between followers of religion; 4) appreciation of the nation's own culture 5) maintain the nation's cultural richness; 5) respect for diversity, ethnicity, religion and culture; 6) please help; 7) anti-discrimination; 8) lifelong pursuit; and 9) responsibilities. Marketer values in the King Ho Ping ritual can be integrated in social studies learning materials in a thematic integrated social studies learning design based on topics, namely the integration of social life with the integration of geography, history, sociology, and economics.

(C) 2020 Universitas Negeri Semarang

$\begin{array}{lr}\text { 『 Alamat korespondensi: } & \text { ISSN 2252-7133 } \\ \text { J1. Raya Sukowati Kapas, Kab. Bojonegoro } & \text { E-ISSN 2548-4648 } \\ \text { Jawa Timur, Indonesia } & \\ \text { E-mail: tom.ekop10@gmail.com } & \end{array}$




\section{PENDAHULUAN}

Dalam Kurikulum 2013 impelementasi pembelajaran IPS di SMP/ MTs berbentuk integrated social studies, yaitu integrasi empat cabang disiplin ilmu yaitu geografi, ekonomi, sejarah, dan sosiologi. Tujuan mata pelajaran IPS itu sendiri untuk membentuk siswa untuk memiliki pemahaman yang baik tentang bangsanya, jiwa patriotisme, dan semangat kebangsaan, serta aktivitas masyarakat di bidang ekonomi dalam ruang wilayah Negara Kesatuan Republik Indonesia.

Tetapi kenyataannya tidaklah mudah dalam mencapai tujuan pendidikan IPS tersebut. Pemahaman tentang bangsa dan semangat kebangsaan dikalangan generasi muda masih rendah.Gejala umum yang nampak yaitu konflik yang melibatkan suku, agama, ras, dan antar golongan atau biasa kita sebut konflik SARA.

Seorang guru mata pelajaran IPS harus mampu mendesain pembelajaran berupa model, media, metode, strategi, dan teknik pembelajaran yang tepat untuk mengembangkan pemahaman akan bangsa dan semangat kebangsaan siswa. Salah satu yang bisa digunakan adalahpembelajaran kontekstual dengan memanfaatkan lingkungan sekitar sebagai sumber belajar.

Banyak sumber belajar dari lingkungan sekitar masyarakat yang bisa dimanfaatkan oleh guru IPS dalam upaya mengembangkan pemahaman akan bangsa semangat kebangsaan siswa salah satunya yaitu ritual King Ho Ping.

Ritual King Ho Ping atau sedekah bumi mempunyai makna pemberian secara sukarela baik jenis maupun jumlah barang yang disedahkan. Ritual sedakah bumi milik etnis Tionghoa melibatkan selain melibatkan etnis Tionghoa dengan kepercayaan Konghuchu juga masyarakat sekitar kelenteng. Nilai-nilai tersebut nampak pada aktualisasi keseharian umat Konghuchu dan masyarakat sekitar dalam menjaga kerukunan umat beragama.

Pembelajaran IPS dengan memanfaatkan ritual King Ho Ping diharapkan dapat membantu siswa dalam mengkaitkan ritual tersebut dengan materi IPS dan mengambil nilai-nilai karakter yang terkandung di dalamnya sehingga diharapkan mereka menjadi siswa yang berkarakter.Dengan terbentuknya siswa yang berkarakter diharapkan dapat meminimalisir konflik SARA di Indonesia.

Karakter itu sendiri diartikan sebagai nilai-nilai yang melandasi cara pandang, berfikir, bersikap, dan bertindak seseorang dalam kehidupan sehari-hari yang terbentuk dari hasil internalisasi berbagai kebajikan (virtues) yang membedakanya dengan orang lain.Nampaknya pembentukan generasi muda yang berkarakter sejalan dengan program pemerintah yaitu Penguatan Pendidikan Karakter atau disebut dengan PPK.Dalam PPK itu sendiri ada lima nilai utama karakter yang saling berkaitan membentuk jejaring nilai yang perlu dikembangkan yaitu nilai karakter 1) religious; 2) gotong royong; 3) nasionalis; 4) integritas; dan 5) mandiri.

Tujuan program PPK adalah menanamkan nilai-nilai pembentukan karakter bangsa secara masif dan efektif melalui implementasi nilai-nilai utama Gerakan Nasional Revolusi Mental (religius, nasionalis, mandiri, gotong-royong dan integritas) yang akan menjadi fokus pembelajaran, pembiasaan, dan pembudayaan, sehingga pendidikan karakter bangsa sungguh dapat mengubah perilaku, cara berpikir dan cara bertindak seluruh bangsa Indonesia menjadi lebih baik dan berintegritas (Kemdikbud, 2017: 1).

Berdasarkan uraian diatas maka tujuan dalam penelitian ini yaitu untuk mengetahui 1) prosesi ritual King Ho Ping dan 2) nilai-nilai karakter dalam ritual King Ho Ping sebagai sumber belajar IPS.

\section{METODE}

Penelitian ini menggunakan pendekatan kualitatif dengan desain penelitian fenomenologi, yaitu sebuah pendekatan yang 
mendiskripsikan makna bagi beberapa individu terhadap pengalaman hidup mereka sebagai sebuah konsep atau sebuah fenomena.Penelitian ini berlokasi di kelenteng Hok Swie Bio Kabupaten Bojonegoro.Waktu penelitian yaitu bulan Agustus 2019.Adapun subyek penelitian dalam penelitian ini adalah pengurus kelenteng Hok Swie Bio Kabupaten Bojonegoro sejumlah dua orang yang dimiliki pengetahuan tentang ritualKing Ho Ping dan dua orang masyarakat sekitar kelenteng.Teknik pengumpulan data yang digunakan dalam penelitian ini adalah wawancara mendalam dan dokumentasi.Instrumen yang digunakan dalam penelitian ini berupa manusia, yaitu peneliti sendiri.Untuk menjaga keabsahan data, digunakan teknik perpanjangan waktu penelitian, triangulasi, dan expert opinion. Teknik analisis data mengacu pada langkah-langkah analisis data kualitatif Creswell (2013: 277) sebagai berikut: (1) mengolah dan mempersiapkan data untuk dianalisis, (2) membaca keseluruhan data dengan membangun general sense atas informasi yang diperoleh dan merefleksikan maknanya secara keseluruhan, (3) menganalisis lebih detail dengan meng-coding data, (4) melakukan proses coding untuk mendiskripsikan setting, orang-orang, kategorikategori, dan tema-tema yang akan di analisis, (5) menyusun diskripsi dari tema-tema dan disajikan kembali dalam narasi/laporan kualitatif, dan (6) mengintepretasi atau memaknai data.

\section{HASIL DAN PEMBAHASAN}

\section{Prosesi ritual King Ho Ping}

Ritual King Ho Ping rutin dilakukan setiap tahun yaitu tanggal 16 bulan tujuh penanggalan Imlek. Ritual ini sudah dilakukan sejak Nabi Purba sebelum Nabi Kongcu lahir. King Ho Ping dalam tradisi Indonesia disebut juga sedekah bumi. Salah satu tujuan dilakukannya ritual ini adalah untuk mendoakan arwah yang tidak punya penerus keturunan dan atau arwah yang tidak didoakan dan sembayangi oleh keluarga atau keturunan nya.
Rangkaian ritual King Ho Ping di kelenteng Hok Swie Bio Bojonegoro diawali dengan pergelaran wayang kulit. Dipilihnya pergelaran ini sebagai wujud perpaduan budaya Tionghoa dengan budaya lokal Indonesia. Bagi masyarakat Jawa, wayang kulit merupakan bagian yang tidak terpisahkan dalam ritual sedekah bumi. Perpaduan dua budaya inilah yang merupakan keunikan dari ritual ini di kelenteng ini. Pergelaran wayang kulit ini terbuka untuk dinikmati masyarakat umum tidak hanya untuk umat Tri Dharma saja.

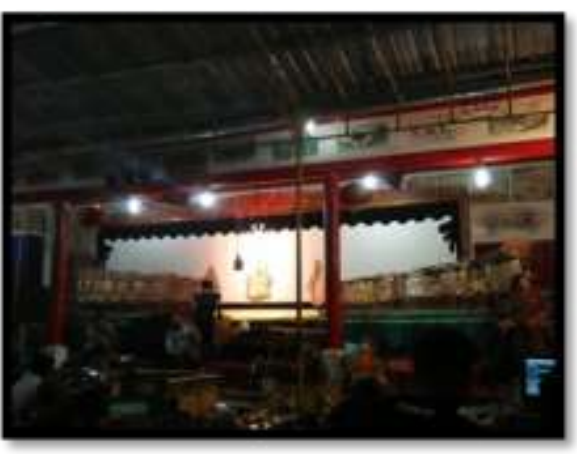

Gambar 1 Pergelaran wayang kulit dalam ritual King Ho Ping

Hari kedua setelah pergelaran wayang kulit dilanjutkan karawitan yaitu kesenian berupa lagu-lagu jawa yang dinyanyikan oleh sinden. Setelah karawitan dilanjutkan atraksi Liong dan Barongsai yang merupakan ritual untuk mengusir roh jahat. Pada atraksi ini dimainkan oleh pemuda-pemuda dari masyarakat sekitar kelenteng. Meskipun bukan bagian dari umat, namun masyarakat sekitar turut serta dalam ritual. Pada malam hari dilanjutkan malam kesenian dan lelang dan ditutup dengan sembahyang ditengah malam.

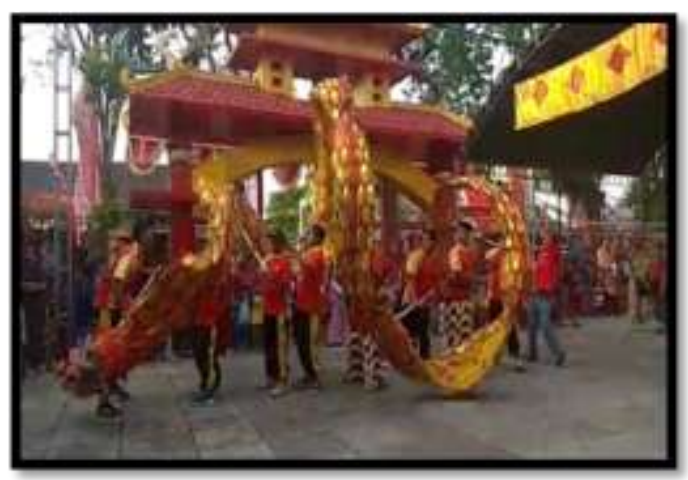

Gambar 2 atraksi Liong da Barongsai 
Hari ketiga sebagai puncak acara dilakukan penyambutan Thay $\mathrm{Su}$ yaitu penyambutan Raja Yanluo (Hanzi) atau Giam Lo Ong (Hokian). Selanjutnya dilakukan sembahyang bersama sebanyak tiga putaran yaitu putaran pertama untuk Tian (Tuhan), putaran kedua untuk Di atau bumi, dan ketiga untuk Ren atau alam. Pada puncak acara sudah tersedia 39 gunungan (Jian) yang nantinya setelah sembahyang selesai untuk diperebutkan oleh masyarakat sekitar. Gunungan atau dalam disebut juga manganan merupakan sumbangan dari berbagai umat yang dipercaya membawa keberkahan apabila berhasil memperolehnya setelah didoakan dalam ritual ini.

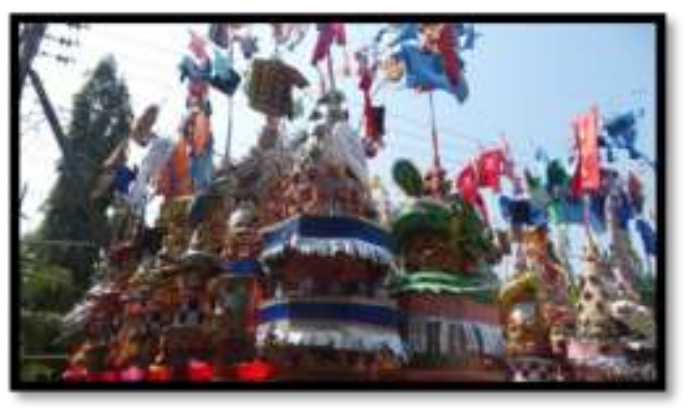

Gambar 3 Gunungan

Selain gunungan, juga terdapat semacam patung dari kertas sebagain perwujudan Raja Yanluo (Hanzi) atau Giam Lo Ong (Hokian) dipercaya sebagai salah satu dewa penjaga pintu neraka salah yang diakhir ritual dibakar sebagai simbol penyempurnaan sembahyang. Nilai-nilai karakter dalam ritual rebutanKing Ho Ping.

\section{Nilai-nilai karakter dalam ritual King Ho Ping} sebagai sumber belajar IPS

Nilai karakter religious dengan sub nilai karakter yang pertama yaitu teguh pendirian dalam menjalankan ajaran agama Konghuchu. Ritual King Ho Ping merupakan salah satu ritual yang sudah dijalankan sejak zaman Nabi Purba dan saat ini hanya kelenteng Hok Swie Bio yang masih menjalankannya.Selain itu ritual ini juga dipercaya membawa keberkahan dari setiap gunungan yang berhasil didapatkan setelah di doakan pada sembahyang. Kedua yaitu sub nilai karakter menghargai perbedaan agama dan kepercayaan yang dalam hal ini nampak pada , dan sub nilai karakter yang terakhir yaitu kerja sama antar pemeluk agama yaitu umat Tri Dharma, Islam, Kristen, dan Katholik dalam mempersiapakn perlengkapan ritual yaitu gunungan. Selain itu ketika atraksi Liong dan Barongsai baik pemeluk dalam hal umat dan non umat memainkannnya bersama-sama.

Nilai karakter nasionalis yaitu dengan sub nilai karakter yang pertama yaitu apresiasi budaya bangsa sendiri, yaitu pergelaran wayang kulit dan karawitan. Meskipun ritual King Ho Ping merupakan budaya asli Tionghoa, namun dalam aktualisasinya di Kelenteng Hok Swie Bio ritual ini dilakukan dengan perpaduan dengan buadaya jawa. Kedua yaitu sub nilai karakter menjaga kekayaan budaya bangsa yaitu tetap mempertahankan budaya bangsa sendiri yaitu pergelaran wayang kulit dan karawitan. Sub nilai karakter yang terakhir yaitu menghormati keragaman, suku, agama, dan budaya yaitu agama Konghuchu serta budaya Jawa dan Tionghoa.

Nilai karakter gotong royong yaitu sub nilai karakter yang pertama yaitu kerjasama dalam mempersiapkan ritual King Ho Ping antar pemeluk agama dan etnis Jawa dan Tionghoa sekitar kelenteng. Sub nilai karakter yang kedua adalah tolong menolong yaitu gunungan berupa makanan dan barang-barang yang diperebutkan oleh masyarakat sekitar sebagai bagian dari tolong-menolong kepada warga yang kurang mampu. Sub nilai karakter yaitu anti diskriminasi yaitu memberikan kesempatan kepada pemeluk agama lain untuk menjalan ritual yang diyakini dan dipercaya.

Nilai karakter mandiri yaitu sub nilai karakter menjadi pemelajar sepanjang hayat dengan selalu mendalami ajaran agama yag dianut dan upaya melestarikannya. Nilai karakter integritas yaitu sub nilai karakter tanggung jawab dalam melaksanakan tugas yang diberikan dalam ritual tersebut.

Nilai-nilai karketr dalam ritualKing $H o$ Ping dapat diintegrasikan dalam materi pembelajaran IPS kelas 8 kompetensi dasar 3.2 
yaitu menganalisis pengaruh interaksi sosial dalam ruang yang berbeda terhadap kehidupan sosial budaya serta pengembangan kehidupan kebangsaan dengan materi pluralitas masyarakat Indonesia dan integrasi dalam kehidupan sosial.Dalam desain pembelajaran IPS terpadu materi ini bisa dikembangkan menjadi tema berdasarkan topik yaitu integrasi kehidupan sosial dengan keterpaduan geografi, sejarah, sosiologi, dan ekonomi.

\section{Pembahasan}

Ritual King Ho Ping merupakan acara rutin tahunan yang dilaksanakan setiap tanggal 16 bulan tujuh penanggalan Imlek di kelenteng Hok Swie Bio Bojonegoro.Dalam pelaksanaannya melibatkan umat Tri Dharma dan masyarakat sekitar yang memiliki keyakinan berbeda serta melibatkan etnis keturunan Tionghoa dan Jawa.Pengurus kelenteng menyediakan gunungan yang diakhir kegiatan diperebutkan oleh umat dan masyarakat secara umum.

Makna dari ritual ini yaitu sebagai rasa syukur kepada Tuhan sekaligus mendoakan arwah orang yang meninggal dan tidak didoakan atau disembahyangi oleh keluarganya. Hal yang membedakan ritual ini dengan ritual yang lain yaitu adanya perpaduan budaya Jawa dengan Tionghoa yaitu pergelaran wayang kulit dan karawitan. Pada akhir ritual yaitu dibakarnya Raja Yanluo (Hanzi) atau Giam Lo Ong (Hokian) dipercaya sebagai salah satu dewa penjaga pintu neraka salah sebagai simbol penyempurnaan sembahyang. Berikut hasil sintesis penelitian.

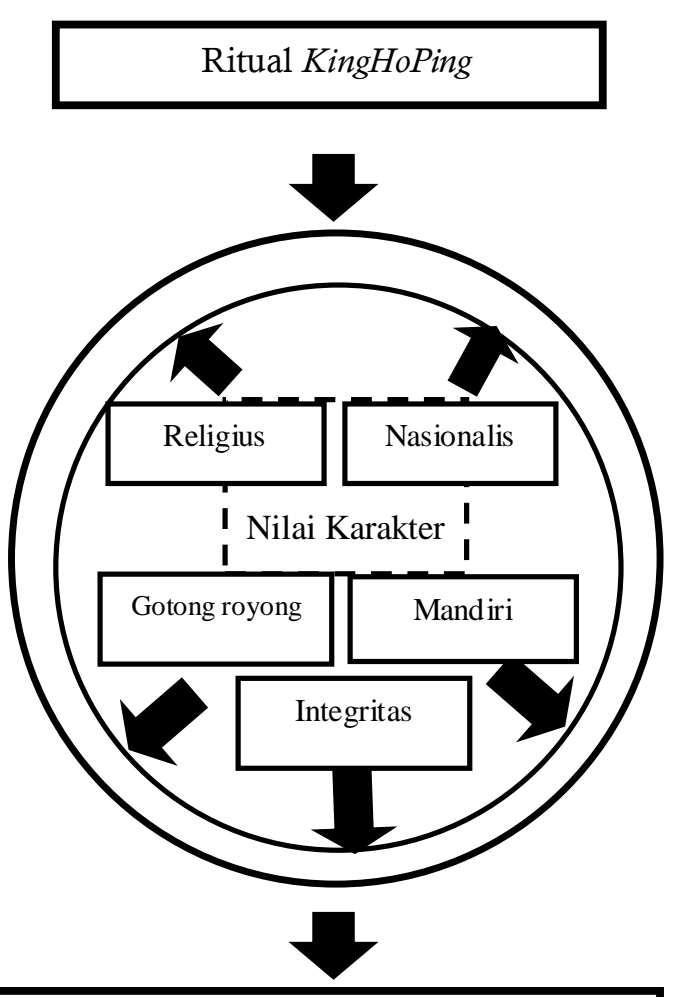

Aktualisasi:1)menghargai perbedaan agama dan kepercayaan; 2) teguh pendirian; 3) kerja sama antar pemeluk agama; 4) apresiasi budaya bangsa sendiri 5) menjaga kekayaan budaya bangsa; 5) menghormati keragaman, suku, agama dan budaya; 6) tolong menolong; 7) anti diskriminasi; 8) pembejara sepanjang hayat; dan 9) tanggung jawab.

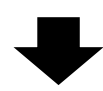

Sumber belajar IPS

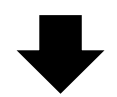

Siswa berkarakter

Gambar 4. Sintesis Penelitian 
Ritual King Ho Ping mengandung lima nilai karakter utama yaitu religious, nasionalis, gotong royong, mandiri, dan integritas membentuk perilaku berkarakter. Sub nilai karakter yang diaktualisasikan dalam kehidupan sehari-hari oleh umat Konghuchu dan masyarakat sekitar yaitu 1) menghargai perbedaan agama dan kepercayaan; 2) teguh pendirian; 3) kerja sama antar pemeluk agama; 4) apresiasi budaya bangsa sendiri 5) menjaga kekayaan budaya bangsa; 5) menghormati keragaman, suku, agama dan budaya; 6) tolong menolong; 7) anti diskriminasi; 8) pembejara sepanjang hayat; dan 9) tanggung jawab. Hasil penelitian yang sama ditunjukkan oleh penelitian Listiyani (2011), bahwa ritual yang dilaksankan oleh kelenteng melibatkan umat Tionghoa dan masyarakat non Tionghoa dapat meningkatkan solidaritas sosial diantara mereka.

Nilai-nilai karakter dari ritual King Ho Ping dapat diintegrasikan pada pembelajaran IPS pada materi integrasi kehidupan social dengan mengenalkan mereka pada bentuk pluralitas masyarakat Indonesia.Pembelajaran pada materi ini bisa dilaksanakan dengan bentuk outdoor activity yaitu siswa mengamati langsung ritual ini dan melaporkannya dalam bentuk proyek pengamatan.Dengan kegiatan pembelajaran IPS seperti ini diharapkan lebih bermakna bagi siswa.Widayati (2019) dalam penelitiannya mengemukakan dengan siswa mengamati langsung pembelajaran di luar kelas dapat menumbuhkan semangat dan mengurangi kejenuhan yang dialami siswa selama pembelajaran di dalam kelas.

\section{SIMPULAN}

Ritual King Ho Ping dimulai dengan acara pergelaran wayang kulit dilanjutkan dengan karawitan dan atraksi Liong serta Barongsai. Puncak ritual dilakukan sembahyang sebanyak tiga kali putaran dan diakhir bunyi gendering sebagai tanda prosesi rebutan gunungan dimulai. Pada akhir ritual dibakarnya Raja Yanluo (Hanzi) atau Giam Lo Ong (Hokian) dipercaya sebagai salah satu dewa penjaga pintu neraka salah sebagai simbol penyempurnaan sembahyang. Sub nilai-nilai karakter yang muncul yaitu 1)menghargai perbedaan agama dan kepercayaan; 2) teguh pendirian; 3) kerja sama antar pemeluk agama; 4) apresiasi budaya bangsa sendiri 5) menjaga kekayaan budaya bangsa; 5) menghormati keragaman, suku, agama dan budaya; 6) tolong menolong; 7) anti diskriminasi; 8) pembejaran sepanjang hayat; dan 9) tanggung jawab. Nilai-nilai karketr dalam ritual King Ho Ping dapat diintegrasikan dalam materi pembelajaran IPS dalam desain pembelajaran IPS terpadu tematik berdasarkan topik yaitu integrasi kehidupan sosial dengan keterpaduan geografi, sejarah, sosiologi, dan ekonomi.

\section{DAFTAR PUSTAKA}

Creswell, John W. (2013). Penelitian Kualitatif dan Desain Riset: Memilih di antara Lima Pendekatan. Jakarta: Pustaka Pelajar.

Tim. (2017). Konsep dan Pedoman Penguatan Pendidikan Karakter Tingkat Sekolah Dasar dan Sekolah Menengah Pertama. Jakarta: Kemdikbud..

Listiyani, Titin. (2011). Partisipasi Masyarakat Sekitar dalam Ritual di Kelenteng Ban Eng Bio Adiwerna. Jurnal Komunitas, 3 (2), hlm. 124-130.

Widayati (2019).Situs Bagelen Sebagai Sumber Belajar IPS di SMP N 7 Purworejo.Jurnal Harmony, 4 (2), hlm.92-97. 